\title{
Una adición para la flora de Chile: Eremocharis confinis I.M.Johnst. (Apiaceae)
}

\section{An addition to the Chilean Flora: Eremocharis confinis I.M.Johnst (Apiaceae)}

\author{
Sebastián TEILLIeR \\ Escuela de Arquitectura del Paisaje, Universidad Central, Santa Isabel 1186, Santiago, Chile. \\ steillier@gmail.com
}

\begin{abstract}
During an expedition to the Inka Trail at Socoroma, Parinacota Province, XV Region of Chile; about $3150 \mathrm{~m}$ altitude, we found a population of Eremocharis confinis I.M.Johnst. (Apiaceae-Umbelliferae), a new adding for the flora of Chile. That species was described by I.M. Johnston at neighboring Perú, at a locality named Candarave, at the Departamento de Tacna. With this found, Eremocharis had two species in Chile: the desertic-schrub E. fruticosa Phil. and the new altiplanic E. confinis.
\end{abstract}

Eremocharis Phil. comprende unas 9 especies que crecen en el norte de Chile y Perú. El género fue descrito por R.A. Philippi en 1860; para nuestro país sólo se ha reportado Eremocharis fruticosa Phil., que es además, la especie tipo del género (Mathias \& Constance 1962). Se trata de un arbusto que crece en el desierto de Atacama en las diversas formaciones vegetales del Desierto Costero de Tocopilla y de Taltal (Gajardo 1994).

Una evaluación de las condiciones ambientales actuales del trazado del Qhapaq Ñan o Camino del Inca, en la provincia de Parinacota, guiada por arqueólogos del Consejo de Monumentos Nacionales de Chile, dio como resultado el hallazgo de una nueva especie de este género: Eremocharis confinis I.M.Johnst., un arbusto decumbente, poco leñoso, muy diferente a $E$. fruticosa y similar a otras especies de la sierra sur de Perú. La especie fue descrita por I.M. Johnston sobre la base de material obtenido por Weberbauer (Fig. 1) en la localidad de Candarave, en el fronterizo Departamento de Tacna; conociéndose, además, un registro en el camino de Tacna a Tarata, en el mismo Departamento (Hutchinson 1834 de 1957). De acuerdo con León \& Monsalve (2006), la especie en Perú crece en ambientes semi-áridos y es conocida solamente de dos localidades en el sur del país (departamento de Tacna, provincia de Tarata); de acuerdo con los mismos autores, aparentemente no ha vuelto a ser recolectada desde 1957. Weberbauer (1945) describió el ambiente de esta especie como dominada por cactáceas columnares y arbustos dispersos.
DESCRIPCIÓN DE LA ESPECIE

Eremocharis confinis I.M.Johnst., Contr. Gray Herb. 85: 173. 1929.

Tipo: Perú: Candarave, Departamento de Tacna, ca. 2950 m de alt. Marzo, 1925. A. Weberbauer 7369 (F).

Subarbusto, tallos decumbentes, poco leñosos, de hasta $40 \mathrm{~cm}$ de altura, muy ramificados (Fig. 1); ramas $3-15 \mathrm{~cm}$ de longitud, finamente surcadas. Hojas carnosas, glabras, de 2-2,5 x 0,5-1,2 cm, palmatisectas, segmentos lineares, trilobulados y mucronados; la base forma un pseudopecíolo, de 1-2 cm de largo, poco dilatado en el tallo. Inflorescencia, una umbela compuesta, pedúnculo de 0,5-2,5 $\mathrm{cm}$ de largo, involucro con brácteas lanceoladas a oblongas, de 1-2 mm de largo; cada rama de la umbela de 3-10 mm de diámetro, con involucelo de 4-7 brácteas y 3-12 flores, verde-amarillentas hasta purpúreas. Cáliz diminuto, sépalos de 0,3-0,5 mm; corola con pétalos orbiculares a obovados, de $1,5 \mathrm{~mm}$ de largo, con el ápice dilatado; estambres de hasta $2,5 \mathrm{~mm}$; estilopodio más corto que los estilos. Mericarpos de $2 \mathrm{~mm}$, ovales, angulosos, prominentes lateralmente, cóncavos dorsalmente, pero no alados (Figs. 2, 3).

De acuerdo con Mathias \& Constance (1962), los caracteres de diagnóstico de la especie serían principalmente sus hojas ternadas, sus umbelas de 3-10 mm de diámetro y su carácter decumbente. En el material chileno no es posible apreciar la "espiniscencia" de las ramas tal como la describen los autores mencionados; es posible que las "espinas" sean una referencia a los pequeños mucrones de los segmentos foliares. 


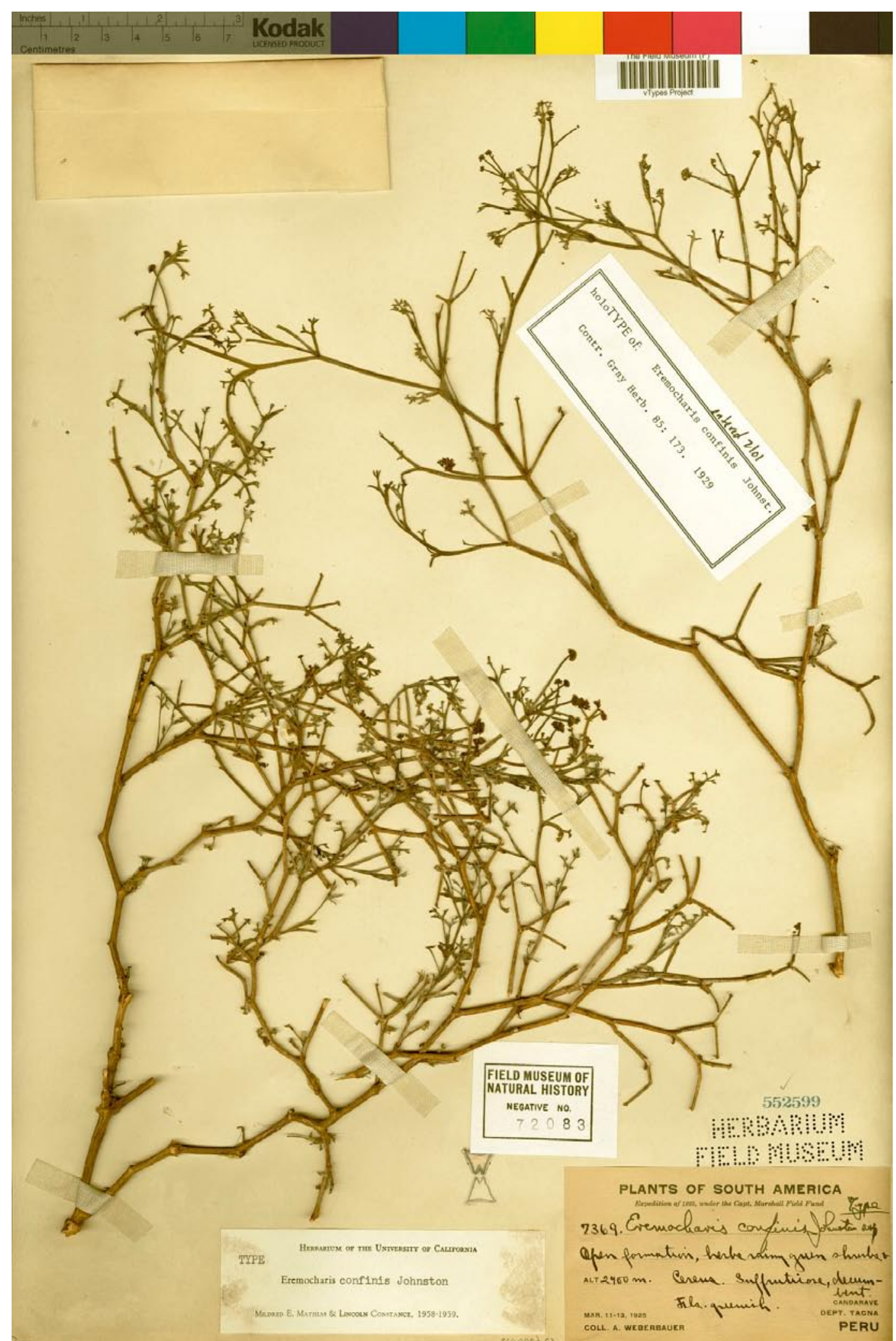

Figura 1. Eremocharis confinis I.M. Johnst. Fotografía del tipo de la especie, Weberbauer 7369 (F).

FigurE 1. Eremocharis confinis I.M. Johnst. Typus of the species, Weberbauer 7369 (F). 
Las plantas crecen en una de las laderas de la quebrada Aroma, en un matorral alto donde los arbustos dominantes eran Lophopappus tarapacanus (Asteraceae) y Balbisia microphylla (Ledocarpaceae). Se observó solo un grupo de plantas que podría comprender varios individuos fuertemente ramificados.

León et al. (2006) y IUCN (2001) la clasifican como una especie en peligro de extinción (B1a) para Perú. Dada que esta es la primera mención para Chile, se necesita más información para atribuirle una categoría de conservación.

Material estudiado

CHILE: Región de Arica y Parinacota (XV). Socoroma, parte baja del faldeo de exposición ecuatorial, quebrada Aroma, $18^{\circ} 14^{\prime} 36.38^{\prime} \mathrm{S}-69^{\circ} 35^{\prime} 17.33^{\prime \prime} \mathrm{W}, 3.150 \mathrm{~m}$, 4-III2009, S. Teillier \& J. Delaunoy 6214 (CONC).

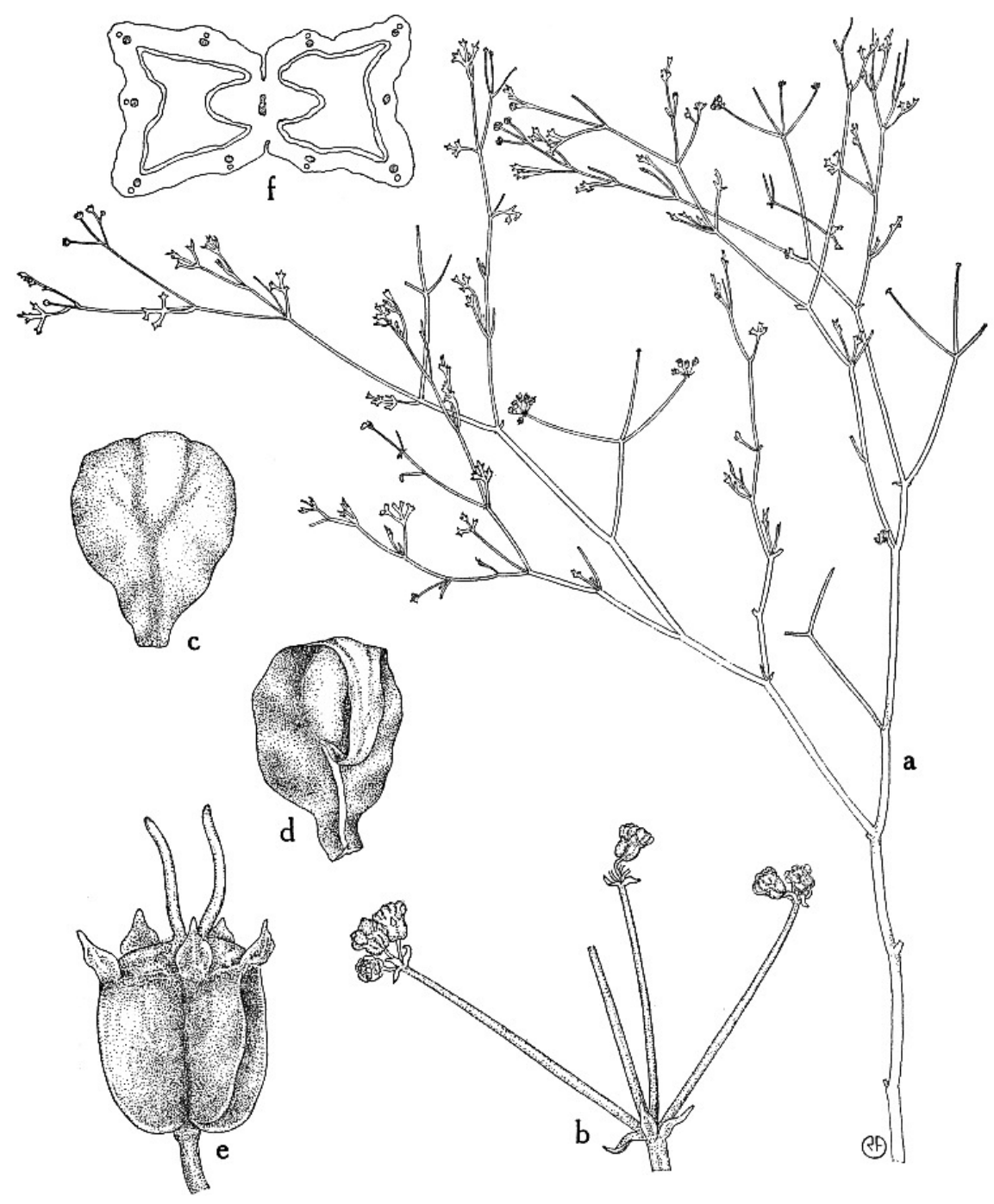

FIGURA 2. Eremocharis confinis I. M. Johnst. A. Hábito x 0,5. B. Grupo de umbelas florecidas x 2,5. C. y D. pétalos x 25 . E. Fruto x $12,5$. F. sección transversal por fruto x 25. Dibujado de Weberbauer 7369 (F), el material tipo (Fuente: Mathias \& Constance 1962).

Figure 2. Eremocharis confinis I. M. Johnst. A. Habit x 0.5. B. Group of flowering umbels x 2.5. C \& D. Petals x 25. E. Fruit 12.5. F. Fruit, transversal section x 25. Drawing from Weberbauer 7369 (Typus) (From: Mathias \& Constance 1962). 
1. Arbustos erguidos de hasta $180 \mathrm{~cm}$ de altura. 50-60 flores en cada rama de la inflorescencia .........Eremocharis fruticosa 1'. Arbustos decumbentes de hasta $30 \mathrm{~cm}$ de altura. 3-12 flores en cada rama de la inflorescencia .....Eremocharis confinis
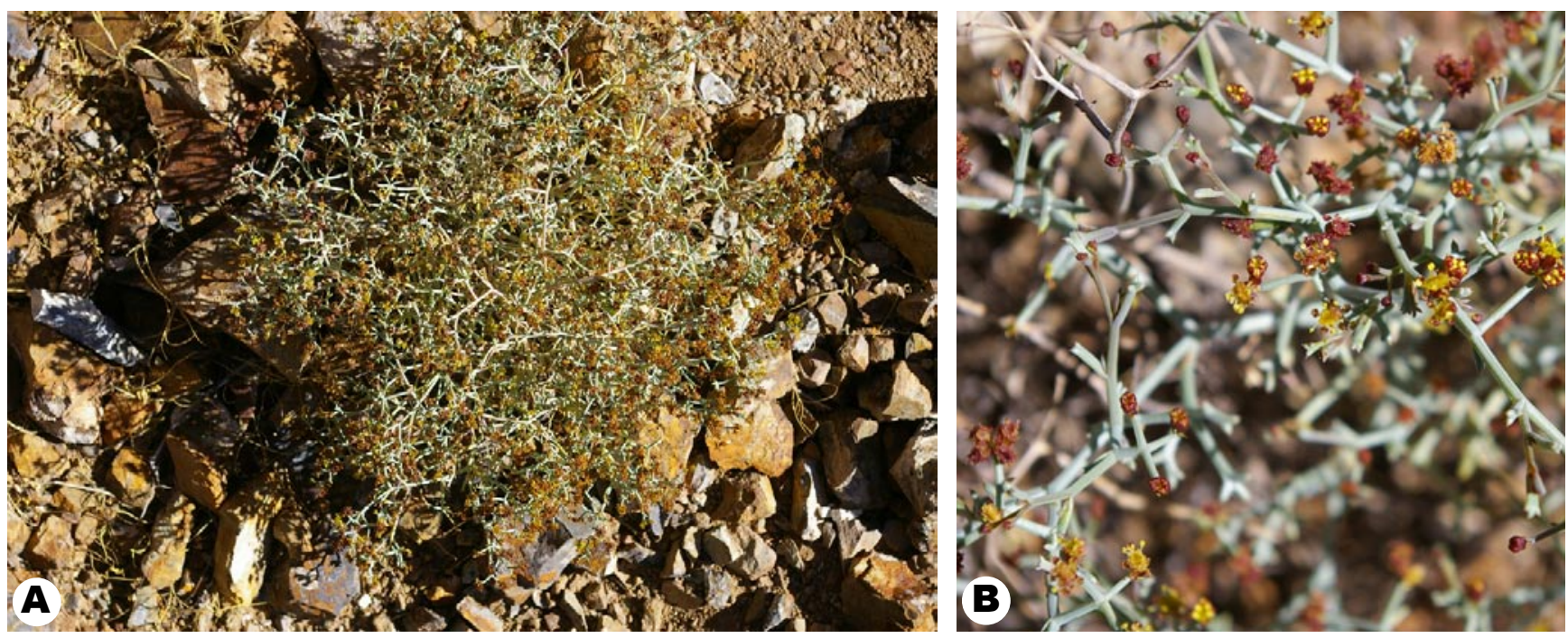

Figura 3. Eremocharis confinis I.M. Johnst. A. Hábito de una planta. B. Ramas terminales, hojas y algunas flores.

FIGURE 3. Eremocharis confinis I.M. Johnst. A. Habit of a plant. B. Terminal branches, leaves and some flowers.

\section{AGRADECIMIENTOS}

A Javiera Delaunoy por la ayuda en terreno. A la consultora ambiental Andalué Ambiental S.A. por las facilidades para el trabajo en terreno. A M. Dillon por la fotografía del tipo de la especie del Field Museum.

\section{BIBLIOGRAFÍA}

Gajardo, R. 1994. La vegetación natural de Chile. Editorial Universitaria. Santiago de Chile. 165 pp.

León, B. \& C. Monsalve. 2006[2007]. Apiaceae endémicas del Perú. Rev. Peru. Biol. Número especial 13 (2): 42s - 45s (diciembre 2006). En: B. León, J. Roque, C. Ulloa-Ulloa, N. Pitman, P.M. Jørgensen \& A. Cano (eds.), El Libro
Rojo de las Plantas Endémicas del Perú. Revista Peruana Biol. 13(núm. 2 especial): 1s-971s. Capítulo consultado en la URL://http://www.scielo.org.pe/pdf/rpb/v13n2/ v13n02a010.pdf (06/06/2010).

León, B., J. Roque, C. Ulloa-Ulloa, N. Pitman, P.M. Jørgensen \& A. CANo. 2006 [2007]. El Libro Rojo de las Plantas Endémicas del Perú. Revista Perú. Biol. 13(núm. 2 especial): 1s-971s. (Fuente directa: Base de datos TROPICOS-Missouri Botanical Garden. URL: http:// www.tropicos.org/Name/1701271 (06/06/2010).

Mathias, M. \& L. Constance. 1962. A revisión of Asteriscium and some related Hydrocotyloid umbelliferae. University of California Publications in Botany 33 (2): 99-184.

Weberbauer, A. 1945. El Mundo Vegetal de los Andes Peruanos. Estudio fitogeográfico. Estación experimental de La Molina. Dirección de Agricultura. Lima-Perú. 776 pp.

Recibido: 26.04.10

Aceptado: 08.06.10 